\title{
Effects of Climate Change on the Season of Botanical Tourism: A Case Study in Beijing
}

\author{
Yaqiong Zang, ${ }^{1,2}$ Junhu Dai, ${ }^{1}$ Zexing Tao, ${ }^{1}$ Huanjiong Wang $\mathbb{D}^{1},{ }^{1}$ and Quansheng Ge $\mathbb{D}^{1}$ \\ ${ }^{1}$ Key Laboratory of Land Surface Pattern and Simulation, Institute of Geographic Sciences and Natural Resources Research, \\ Chinese Academy of Sciences, Beijing 10010, China \\ ${ }^{2}$ University of Chinese Academy of Sciences, Beijing 10049, China
}

Correspondence should be addressed to Huanjiong Wang; wanghj@igsnrr.ac.cn and Quansheng Ge; geqs@igsnrr.ac.cn

Received 24 October 2019; Revised 14 March 2020; Accepted 30 June 2020; Published 17 July 2020

Academic Editor: Budong Qian

Copyright ( 92020 Yaqiong Zang et al. This is an open access article distributed under the Creative Commons Attribution License, which permits unrestricted use, distribution, and reproduction in any medium, provided the original work is properly cited.

\begin{abstract}
Climate change could affect botanical tourism by altering the plant phenology (e.g., flowering and leaf coloring date) and the physical comfort of tourists. To date, few studies have simultaneously considered the influence of plant phenology and physical comfort on the travel suitability of botanical tourism. Taking Beijing as an example, this study used phenological data of 73 species from 1963 to 2017 to construct a phenological ornamental index (POI) according to the flowering and leaf coloring date of ornamental plant. The climate comfort index (CCI) of tourism was calculated by using meteorological data of the corresponding periods. Finally, the travel suitability index (TSI) was constructed by integrating the two indices (POI and CCI). The POI showed that the best period for spring flower viewing was from April 4 to May 10, while the best period for autumn leaves viewing was from October 11 to November 6 on average. According to the variation of the CCI within the year, the most comfortable period for spring tourism was matched with the best period for spring flower viewing (April 4 to June 1), but the most comfortable period for autumn tourism (September 4 to October 19) was earlier than the best period for autumn leaves viewing. The TSI indicated that the best periods for spring and autumn botanical tourism were April 7 to May 10 and October 10 to November 7, respectively. Based on the climate data under different scenarios (representative concentration pathways 4.5 and 8.5), we simulated the climate and phenological suitability for botanical tourism in the next thirty years. The results showed that the best period for spring botanical tourism during 2040-2050 was earlier and the period for autumn botanical tourism was later than that in the past 55 years. Meanwhile, the duration would shorten by 2-7 days for both seasons. This study provided a reference for assessing the impact of global climate change on the best season of botanical tourism.
\end{abstract}

\section{Introduction}

The plants provide an opportunity to serve as botanical tourism in which many different forms of tourism activities can be carried out, such as the cherry blossom festivals in Japan, the rose festival in Bulgaria, tulip festival in Holland, and the maple syrup festivals in Canada. These tourism activities are profoundly affected by climate change [1]. On the one hand, the landscape of botanical tourism is related to plant phenophases (e.g., flowering and leaf coloring date), which responded sensitively to climate change [2]. On the other hand, climate change exerts a direct influence on human comfort by altering meteorological factors such as temperature, humidity, precipitation, wind speed, and sunshine. Thus, climate change could affect botanical tourism by simultaneously changing plant phenology and tourists' physical comfort $[3,4]$.

Over the past several decades, the best time for botanical tourism, such as spring flower viewing and autumn leaves viewing, was altered under the background of climate change. For example, based on phenological data of 232 plant species from 1985 to 2011 on the island of Guernsey in the English Channel, the significantly earlier beginning of flowering and shorter flowering duration was found [5]. Another study based on a 73-year long data series of first flowering dates for 25 species from north-temperate Sweden showed that most time-series of first flowering dates exhibited tendencies towards earlier flowering [6]. A climate-associated shortening of 
the flowering season was also significant in high-Arctic Greenland [7]. Regarding the autumn season, the temperature rise led to a later beginning of leaf coloring from 1978 to 2016 in Japan, which made the number of visitors increase by more than 3\% [8]. The leaf senescence of deciduous trees in the northern hemisphere became later over time, especially in the low-latitude area [9].

For assessing the potential impacts of climate change on botanical tourism, many studies focused on predicting the spring flower phenology. For instance, a process-based model was developed to predict peak bloom dates of flowering cherry trees in the Tidal Basin, Washington, DC [10]. Hur et al. [11] used the seasonal prediction from the global and regional climate models to evaluate the forecast capability of the first flowering date of cherry, peach, and pear over South Korea. Recently, several studies noticed the impact of phenological change on botanical tourism. For example, Sakurai et al. [12] explored the perceptions of Japanese residents regarding climate change impacts on culturally significant events and found that most (92\%) managers of festival-dependent businesses were concerned about global warming because it affected the flowering timing of cherry trees and income of cherry blossom festivals. In Beijing, the administrator of Jingshan Park scheduled the peony blossom festival date following the variation of peony FFD [13].

Besides phenology, the degree of climate comfort could directly affect botanical tourism [14]. The early evaluation of climate comfort was usually based on the empirical model of human comfort. The empirical models reflected the subjective feeling or physiological reaction of people and were built by experience or statistical methods. The typical empirical models included effective temperature (ET) [15], wet bulb globe temperature (WBGT) [16], temperature-humidity Index (THI) [17], and Wind Chill Index (WCI) [18], which considered the impact of air temperature, relative humidity, wind speed, and solar radiation. Empirical indices were simple to be calculated and easy to be understood by the public. In the late 1960s, advances in biometrics and computer technology led to the rapid development of climate comfort indices based on human heat exchange models $[19,20]$, such as perceived temperature (PT) [21], standard effective temperature (SET) [22], and physiological equivalent temperature (PET) [23], which comprehensively considered the meteorological factors (air temperature, relative humidity, wind speed, and solar radiation), human metabolic rate, clothing, and individual parameters. However, human heat exchange was a very complex process and difficult to accurately calculate. Thus, the above indices based on human heat exchange were not widely used. Recently, scientists developed a universal thermal climate index (UTCI), which was regarded as one of the most comprehensive indices for calculating heat stress in outdoor space $[24,25]$. The input data for calculating UTCI included meteorological and nonmeteorological (metabolic rate and clothing thermal resistance) data [26]. The parameters that were taken into account for calculating UTCI involve dry temperature, mean radiation temperature, the pressure of water vapor or relative humidity, and wind speed. A recent study showed that the significant correlations were detected between UTCI and previous indices of climate comfort [27], indicating that the earlier indices of climate comfort were still valid.

In recent years, a large number of studies chose one of the indices or combine several indices to evaluate the local climate comfort according to the research purpose and study area. For instance, Mihăilă et al. [28] used an hourly database for the period 1961-2015 to calculate the PET index and outline a series of changes that were likely to intervene in the relationship between climate and tourism in north-eastern Romania in the immediate future. Cheng and Zhong [29] investigated tourism climate conditions in Grand ShangriLa from 1980 to 2016 using a tourism climate index (TCI) and found that the number of annual and monthly goodweather days increased over most of the area under the influence of climate warming. In Beijing, China, the level of tourism comfort showed an increasing trend for all seasons, which was favorable for the development of tourism [30]. These studies provided examples for assessing the impact of climate comfort on tourism in specific tourism destinations.

To date, few studies have considered the effect of plant phenology and climate comfort on botanical tourism simultaneously. In order to fill in this gap, we chose Beijing as the research area where botanical tourism was well developed and analyzed the impact of climate change on the phenology and physical comfort of tourists. First, we developed a phenological ornamental index (POI) based on phenological data of 73 species from 1963 to 2017. Second, using meteorological data, we calculated annual changes in the climate comfort index (CCI). Combining the POI and CCI, the travel suitability index (TSI) of botanical tourism was constructed. Finally, by using the climate data simulated under different representative concentration pathways (RCP), we predicted the changes in POI, CCI, and TSI from 2020 to 2050. This study aimed to reveal the impact of climate change on the season of botanical tourism and provide references for the tourism administrators to choose the appropriate time to arrange activities of botanical tourism.

\section{Materials and Methods}

2.1. Study Area. Beijing, located in northern China, has a temperate semihumid climate. In the urban area of Beijing, the mean annual temperature was $12.53^{\circ} \mathrm{C}$ (averaged from 1963 to 2017). The monthly maximum and minimum temperatures were $25.46^{\circ} \mathrm{C}$ in July and $-3.41^{\circ} \mathrm{C}$ in January, respectively. The annual total precipitation was $560.87 \mathrm{~mm}$, and the annual mean wind speed was $2.44 \mathrm{~m} / \mathrm{s}$. In Beijing, there were many tourism activities relating to botanical tourism, such as peach blossom festival at Beijing Botanical Garden, peony festival at Jingshan Park, cherry blossom festival at Yuyuantan Park, and red leaf festival at Fragrant Hills Park. Therefore, Beijing was an ideal place to study the impact of climate change on botanical tourism.

2.2. Data Source. All phenological data were derived from China Phenology Observation Network (CPON). These data were observed at the Summer Palace $\left(39.992^{\circ} \mathrm{N}, 116.266^{\circ} \mathrm{E}\right)$, 
which was located in northwestern Beijing (Figure 1). Considering that the urban area of Beijing has a similar elevation, we believed that the phenological data at one site could generally represent the whole urban area (although difference existed among individuals). Four phenophases of 73 woody plants from 1963 to 2017in Beijing were investigated (Table S1). Most of these species were representative ornamental plants with relatively complete observation data. We investigated the phenophases which were closely related to the botanical tourism, including the date of first flowering (FFD), end of flowering (EFD), beginning of leaf coloring (BLC), and end of leaf coloring (ELC).

The daily meteorological data in Beijing from 1963 to 2017 were downloaded from China meteorological data service center (http://data.cma.cn/). We used the data from the Haidian meteorological station $\left(39.987^{\circ} \mathrm{N}, 116.290^{\circ} \mathrm{E}\right)$, including mean, maximum, and minimum air temperature, relative humidity, and wind speed. Future climate data were derived from the Coupled Model Intercomparison Project Phase 5 (CMIP5) of the World Climate Research Programme (WCRP). We obtained future climatic datasets generated by the Community Climate System Model version 4 (CCSM4) under the representative concentration pathway (RCP) 4.5 and RCP 8.5 [31]. The dataset covered the period from 2020 to 2050, including daily mean, maximum, and minimum air temperature, relative humidity, and wind speed with a spatial resolution of $1.4^{\circ} \times 1.4^{\circ}$. According to Beijing's geographic coordinates, we extracted the meteorological factors of the corresponding pixel in the future climate data, and the statistical downscaling method was used to convert the data to the local scale [32].

2.3. Construction of Travel Suitability Index. Plants were very attractive to tourists when they were in flowering or leaf coloring. Therefore, we first constructed a new phenological ornamental index (POI) to describe the number of species in flowering or leaf coloring at each day of the year. The POI could reflect whether it was an appropriate time to travel for spring flower viewing or autumn leaves viewing. Furthermore, climate conditions could affect the physical comfort of tourists. Thus, we calculated the daily climate comfort index (CCI) based on two previously proposed indexes to describe whether the climate was comfortable for traveling. Finally, the travel suitability index (TSI) was constructed by considering both POI and CCI.

2.3.1. Phenological Ornamental Index. To date, there was no index to measure the impact of phenology on botanical tourism. Therefore, we introduced a POI in this study. First, we counted the number of species in flowering (from the first flowering date to the end of the flowering date) or in leaf coloring (from the beginning date of leaf coloring to the end date of leaf coloring) for each day of the year. Subsequently, the daily changes in the number of species in flowering or leaf coloring were smoothed by using the 5-day moving average method. The POI at each date was defined as the number of species in flowering and leaf coloring (after smoothing).
Within each year, two peaks appeared in the daily POI curve. The first peak occurred in spring because most of the plants flowered in this season. In the first 6 months of the year, the period when POI was larger than half of the maximum was defined as the best period for spring flower viewing. Similarly, in the last six months of the year, the period when POI was larger than half of the maximum was defined as the best period for autumn leaves viewing.

2.3.2. Climate Comfort Index. As mentioned in the Introduction section, a variety of climate comfort indices had been proposed [33]. Among them, the temperature-humidity index (THI) and the wind chill index (WCI) were frequently used in previous studies. According to the environmental background conditions on which they were built, THI was more applicable to the warm environment, while WCI was more suitable to the cold environment. Therefore, in this study, we combined these two indices to make it more applicable to a temperate climate.

THI is a measure of the reaction of the human body to a combination of heat and humidity [34], and the equation for THI is

$$
\mathrm{THI}=(1.8 \cdot t+32)-0.55(1-f) \times(1.8 \cdot t-26),
$$

where $t$ is air temperature $\left({ }^{\circ} \mathrm{C}\right)$ and $f$ is relative humidity (\%).

WCI could reflect the effect of wind on the temperature which humans perceive [35]. The equation for WCI is

$$
\mathrm{WCI}=(10 \sqrt{v}-v+10.5) \times(33-t),
$$

where $t$ is air temperature $\left({ }^{\circ} \mathrm{C}\right)$ and $v$ is wind speed $(\mathrm{m} / \mathrm{s})$.

According to the values of THI and WCI, we gave different scores to quantify the level of climate comfort. Higher scores suggested a more comfortable climate (Table 1). The CCI was defined as the average of THI and WCI score:

$$
\mathrm{CCI}=\frac{S_{\mathrm{THI}}+S_{\mathrm{WCI}}}{2},
$$

where CCI is the climate comfort index and $S_{\mathrm{THI}}$ and $S_{\mathrm{WCI}}$ are the scores of THI and WCI, respectively. Similarly, within a year, two peaks appeared in the daily CCI curve. The period when CCI was larger than 7 was defined as the most comfortable period.

2.3.3. Travel Suitability Index. We first calculated the product of POI and CCI $(X)$ to measure the overall impact of phenology and climate on the suitability of botanical tourism ((4)). Subsequently, we normalized the value of $X$ to $0-1$ range using (5). The normalized value could be defined as TSI.

$$
\begin{gathered}
X=\text { POI } \cdot \text { CCI, } \\
\text { TSI }=\frac{X-X_{\min }}{X_{\max }-X_{\min }},
\end{gathered}
$$

where $X$ represents the product of POI and CCI. $X_{\max }$ and $X_{\min }$ are the maximum and minimum values of TSI within a year, respectively. 


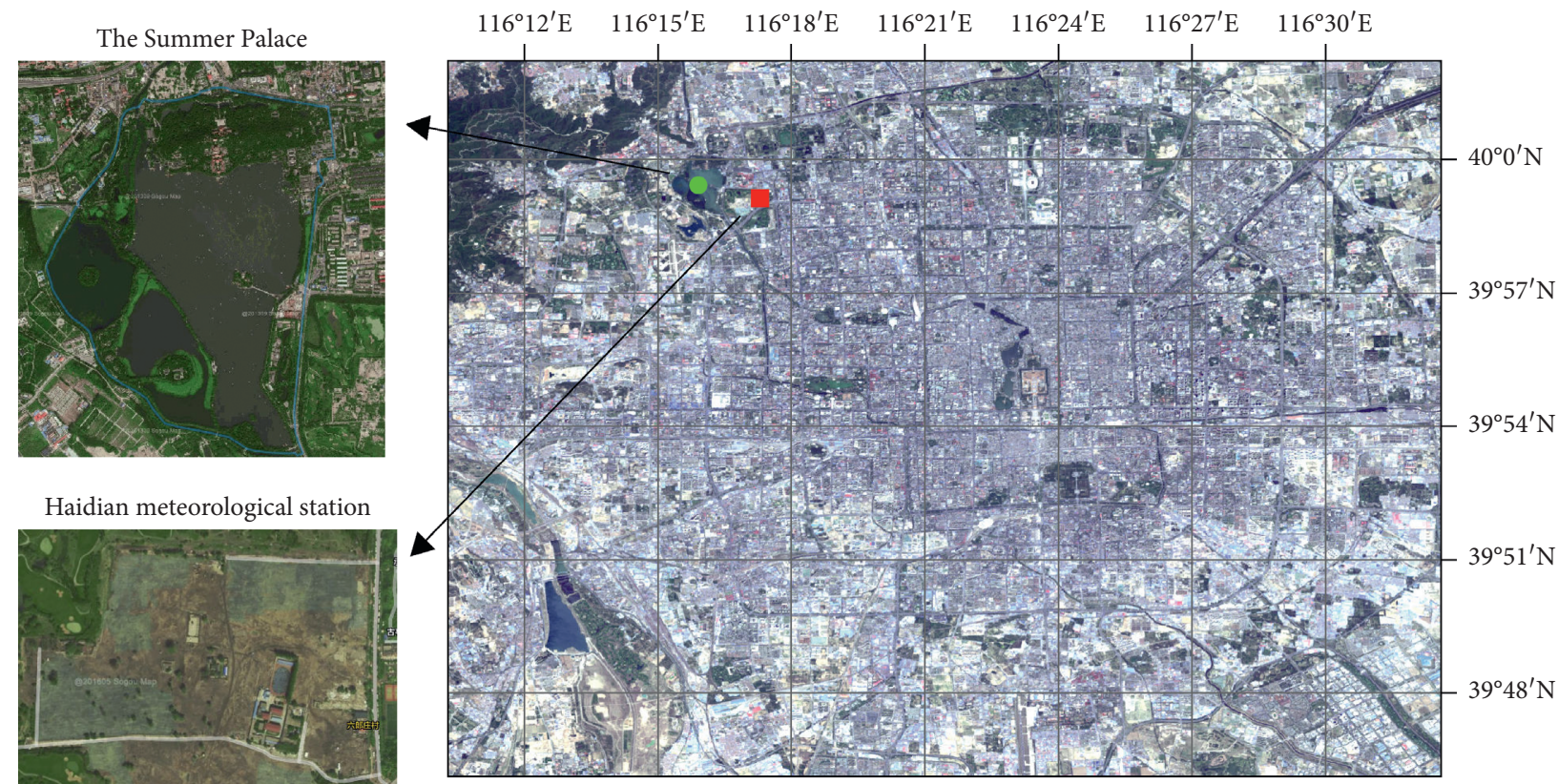

FIGURE 1: The locations of phenological observation and meteorological stations in Beijing. The phenological data were collected in the Summer Palace, and the meteorological data was derived from the Haidian meteorological station. The image of the urban area of Beijing is Landsat 8 image observed on May 18, 2015, courtesy of the US Geological Survey. The subplots of each station were downloaded from Sogou Map (http://map.sogou.com/).

TABLE 1: Classification and score of the temperature-humidity index (THI) and wind chill index (WCI).

\begin{tabular}{lccc}
\hline The level of climate comfort & $\begin{array}{c}\text { THI } \\
\text { value }\end{array}$ & WCI value & Score \\
\hline Extremely cold and uncomfortable & $<40$ & $>1000$ & 1 \\
Cold and uncomfortable & $40 \sim 45$ & $800 \sim 1000$ & 3 \\
Slightly cold and uncomfortable & $45 \sim 55$ & $600 \sim 800$ & 5 \\
Cool and comfortable & $55 \sim 60$ & $300 \sim 600$ & 7 \\
Pleasantly cool and very & $60 \sim 65$ & $200 \sim 300$ & 9 \\
comfortable & $65 \sim 70$ & $50 \sim 200$ & 7 \\
Warm and comfortable & $70 \sim 75$ & $-80 \sim 50$ & 5 \\
A little hot and comfortable & $75 \sim 80$ & $-160 \sim-80$ & 3 \\
Hot and uncomfortable & $>80$ & $<-160$ & 1 \\
Extremely hot and uncomfortable & & &
\end{tabular}

Following the above steps, we calculated the daily TSI from 1963 to 2017. For a certain year, two peaks appeared in the TSI curve. Thus, there were two periods during which the TSI was larger than 0.5. The first and second periods were defined as the best periods for spring and autumn botanical tourism, respectively. The linear trend in the start date, end date, and duration of the best period was calculated by regression of these dates against the year.

2.4. Simulation of Travel Suitability Index from 2020 to 2050. In order to predict the POI in the future, we first used phenological models to predict the flowering and leaf coloring phenology of each plant. The Unified model was chosen for simulating future FFD and EFD, and the temperature-photoperiod model was chosen for simulating BLC and ELC. The detailed information on the model formulas could be found in previous studies [36, 37].
Based on the phenological and meteorological data from 1963 to 2017, we calibrated the Unified model and temperature-photoperiod model for each species and phenophase. We fitted the optimal parameters for each model by using the simulated annealing method based on the leastsquares principle, that is, the parameters with the minimum sum of the squares of the residuals [38]. The goodness of fit $\left(R^{2}\right)$ and root mean square error (RMSE) were calculated to assess the error of the phenological models. By using the temperature data under two climate scenarios and the calibrated phenological models, we simulated the FFD, EFD, BLC, and ELC of each plant from 2020 to 2050. Subsequently, future POI could be calculated by using the method described in Section 2.3.1

Future changes in CCI could be simulated by using future climate data and methods described in Section 2.3.2. At last, the yearly changes in TSI (2020-2050) could be calculated.

\section{Results}

3.1. Changes in the Phenological Ornamental Index. Figure 2 shows the POI averaged from 1963 to 2017. The POI curve showed that the best period for spring flower viewing ranged from April 4 to May 10, which lasted 36 days. The best period for autumn leaves viewing was between October 11 and November 6, which lasted 27 days. From 1963 to 2017, the start and end date of the best period for spring flower viewing advanced by 0.23 days/year $(P<0.01)$ and 0.08 days/year $(P>0.05)$, respectively (Figure $3(\mathrm{a}))$. The duration of the best period for spring flower viewing was extended by 0.15 days/year $(P>0.05)$. Regarding the autumn leaves viewing, the start and end date of the best period exhibited significantly delayed trends of 0.35 days/year and 


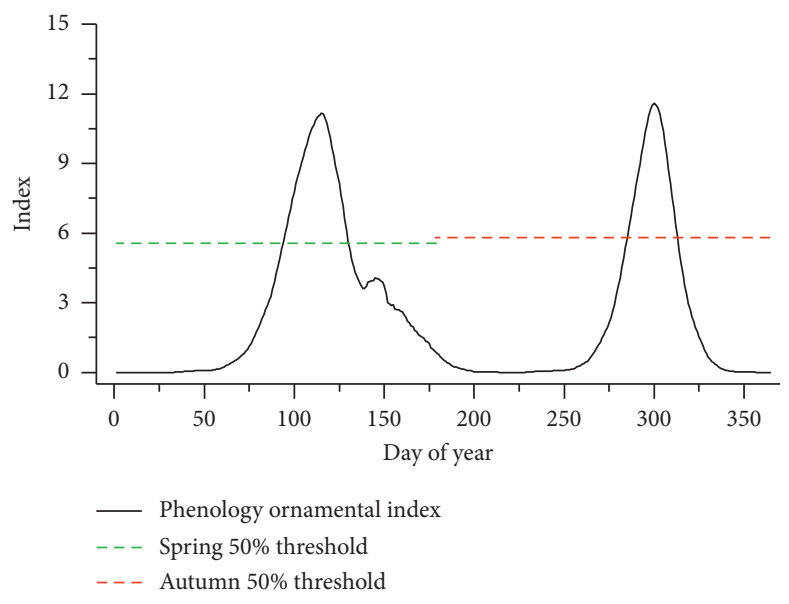

FIgURE 2: Multiyear mean phenological ornamental index (1963-2017) in Beijing.

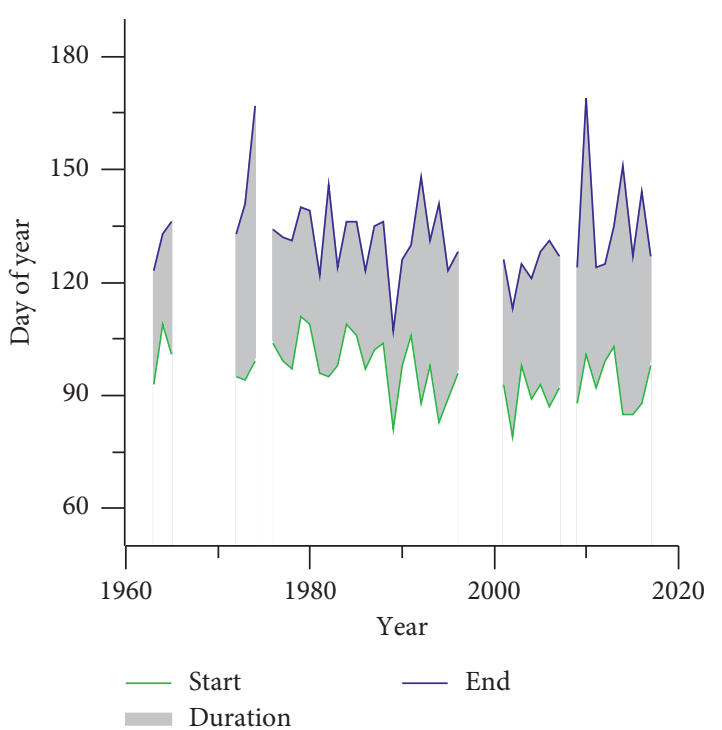

(a)

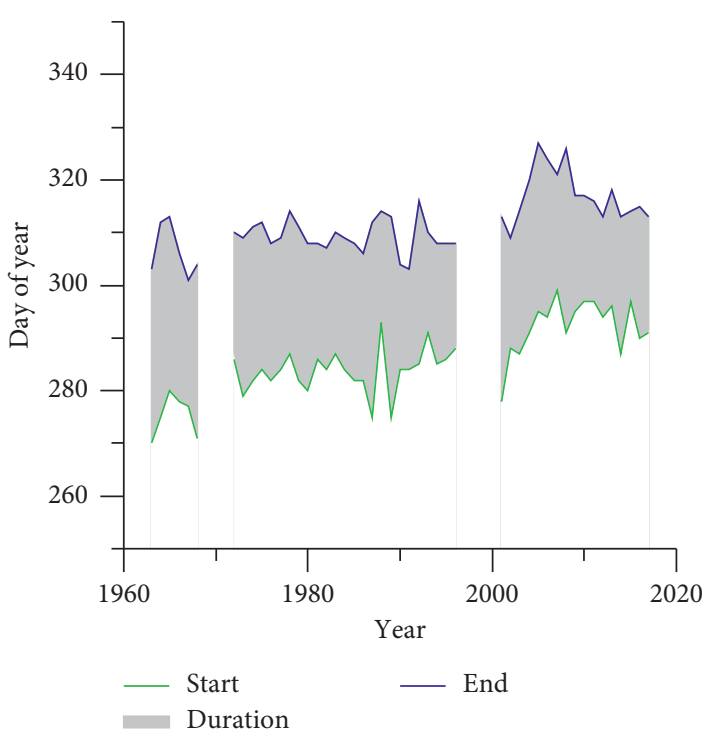

(b)

FIGURE 3: Interannual variation in the start and end date of the best period for spring flower viewing (a) and autumn leaves viewing (b) from 1963 to 2017.

0.22 days/year $(P<0.01)$, respectively (Figure $3(\mathrm{~b}))$. Due to the more considerable delay in the start date than the end date, the duration of the best period for autumn leaves viewing shortened by 0.13 days/year over the past 55 years $(P<0.01)$.

\subsection{Changes in the Climate Comfort Index. The mean CCI in} Beijing over the past 55 years was shown in Figure 4(a). Similar to the POI, the curve of CCI within a year was bimodal. The most comfortable periods $(\mathrm{CCI}>7)$ in spring and autumn were April 4 to June 1 and September 4 to October 19, respectively. The most comfortable period in spring was highly coincident with the best period for spring flower viewing, but, in autumn, the most comfortable period was earlier than the best period for autumn leaves viewing.
From the perspective of interannual changes (Figure 4(b)), the CCI value during the most comfortable period in spring showed a smaller interannual variation than that in autumn, ranging from 7.46 (1976) to 7.85 (1970). The amplitude of change in mean CCI of the most comfortable period in autumn was larger, ranging between 7.36 (2017) and 8.13 (1990). The mean CCI value of the most comfortable period did not show significant linear trends in both spring and autumn $(P>0.05)$.

3.3. Changes in the Travel Suitability Index in the Past. Figure 5 shows the multiyear mean of TSI in Beijing. There were two best periods for botanical tourism. The best period for spring botanical tourism started on April 7 and ended on May 10, with a duration of 33 days. The best period for 


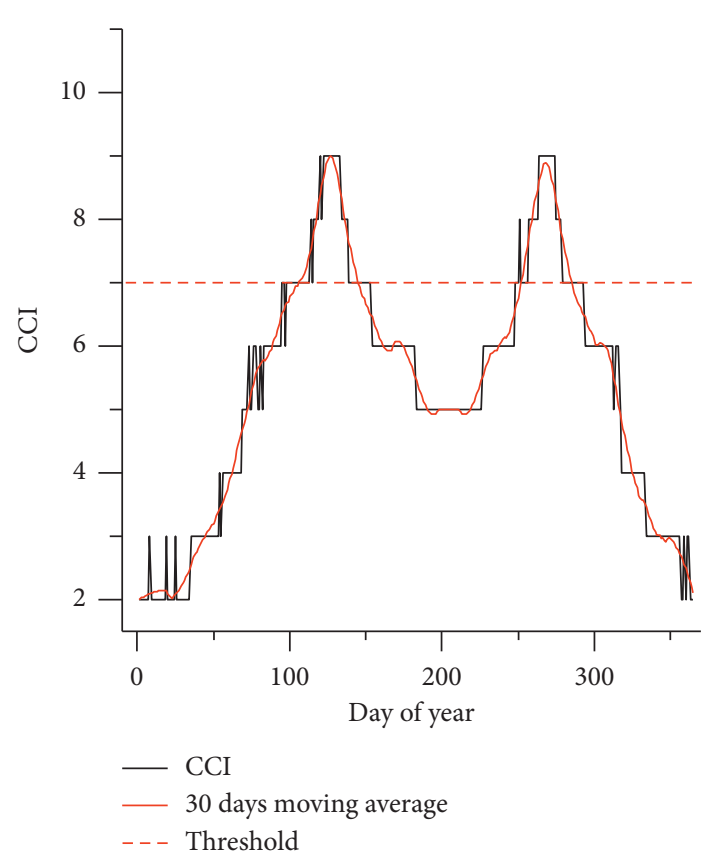

(a)

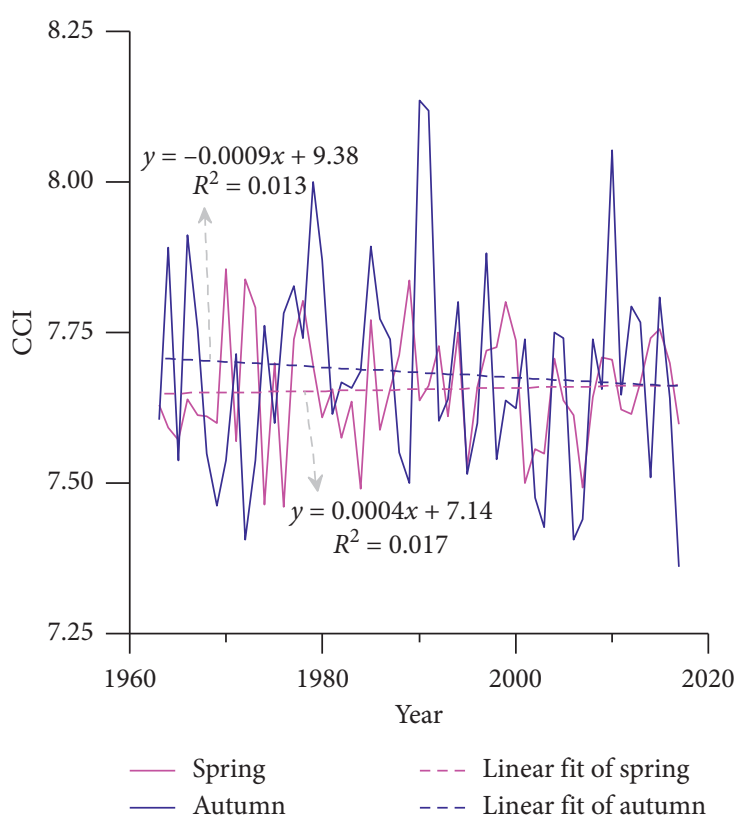

(b)

Figure 4: Multiyear mean and interannual variation of climate comfort index (CCI).

autumn botanical tourism was from October 10 to November 7 , with a duration of 28 days.

The interannual changes in the best periods for spring and autumn botanical tourism were illustrated in Figure 6. In spring, the start and end of the best period became significantly earlier from 1963 to 2017 with a rate of 0.18 days/year and 0.26 days/year $(P<0.01)$, respectively. Because the end date advanced more than the start date, the duration was shortened by 0.08 days/year $(P>0.05)$. In autumn, the start and end dates of the best period were significantly delayed by 0.35 and 0.22 days/year $(P<0.01)$, respectively. As a result, the duration was shortened significantly by 0.13 days/year $(P<0.01)$.

3.4. Changes in Travel Suitability Index in the Future. The phenological models were used to simulate the phenophases of each species from 2020 to 2050. The results of model validity were shown in Table S2. For FFD, the RMSE of the cross-validation was 5.98 days, and the average $R^{2}$ was 0.61 . Regarding EFD, the mean RMSE was 8.89 days, and the $R^{2}$ was 0.52 . For BLC and ELC, the mean RMSE of the crossvalidation was 10.45 days and 9.33 days with $R^{2}$ of 0.34 and 0.31 , respectively. Thus, the phenological models could accurately simulate the phenophases, especially for FFD and EFD. Using the climate data under RCP 4.5 and RCP 8.5 and the phenophases simulated by phenological models, the POI (shown in Figure S1), CCI (shown in Figure S2), and TSI (shown in Figure 6) for the next 30 years were calculated.

Based on the simulated TSI (Figure 7), the best periods for spring botanical tourism during 2040-2050 were similar between RCP 4.5 (March 31 to April 26) and RCP 8.5 (March 29 to April 25). However, the start date and end date in the future were earlier, and the duration was shorter than the past 55 years (April 7 to May 10). The best periods for autumn botanical tourism during 2040-2050 were from October 16 to November 11 under RCP 4.5 and October 19 to November 11 under RCP 8.5. Compared to the past 55 years (from October 10 to November 7), the start and end dates of the best period for autumn botanical tourism would be predicted to be 6-9 days and 4 days later, and the duration would be 2-5 days shorter during 2040-2050.

Figure 8 shows the interannual variation in the start and end date of the best periods for botanical tourism from 2020 to 2050. In spring, the trends in the start and end dates were0.06 days/year $(P>0.05)$ and -0.15 days/year $(P<0.05)$ under RCP 4.5, respectively. Under RCP 8.5, the start date and end date advanced by 0.41 days/year $(P<0.01)$ and by 0.31 days/year $(P<0.01)$, respectively. During the period 2020-2050, the duration of the best period for spring botanical tourism was shortened by 0.09 days/year $(P>0.05)$ and 0.10 days/year $(P>0.05)$ under RCP 4.5 and RCP 8.5, respectively.

The best period for autumn botanical tourism under two scenarios is shown in Figures 8(b) and 8(d). Under RCP 4.5, both start and end date were significantly delayed by 0.31 days/year $(P<0.01)$, and the duration exhibited no obvious trend from 2020 to 2050 . Under RCP 8.5, the start date was delayed with a rate of 0.33 days/year $(P<0.05)$, and the delay in the end date was 0.27 days/year $(P<0.05)$, resulting in a shortened duration (0.06 days/year, $P>0.05$ ).

\section{Discussion}

From the perspective of phenology, we constructed a POI to describe the best period for spring flower viewing and 


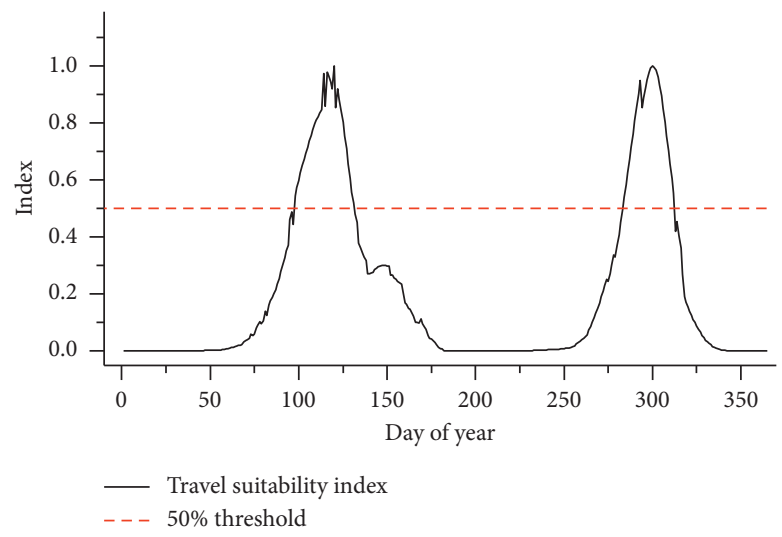

FIGURE 5: Multiyear (1963-2017) mean travel suitability index in Beijing.

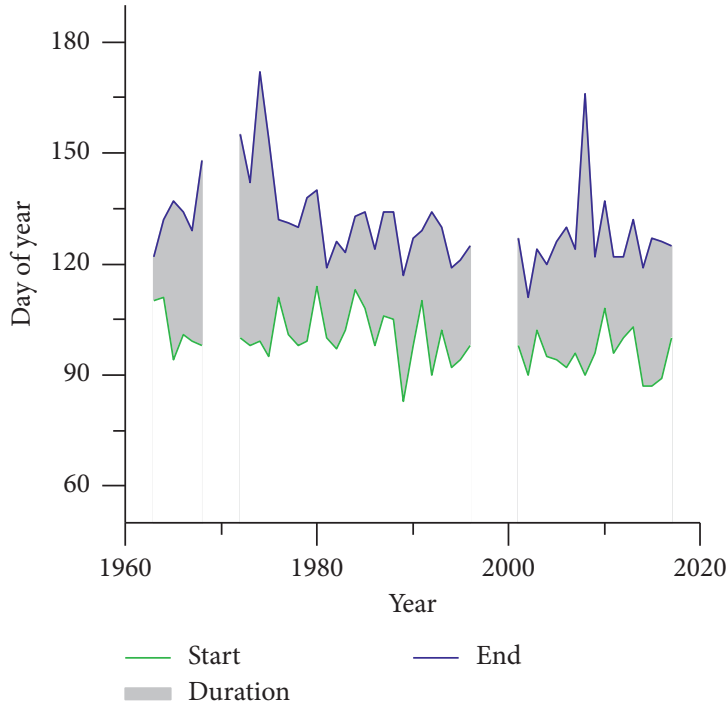

(a)

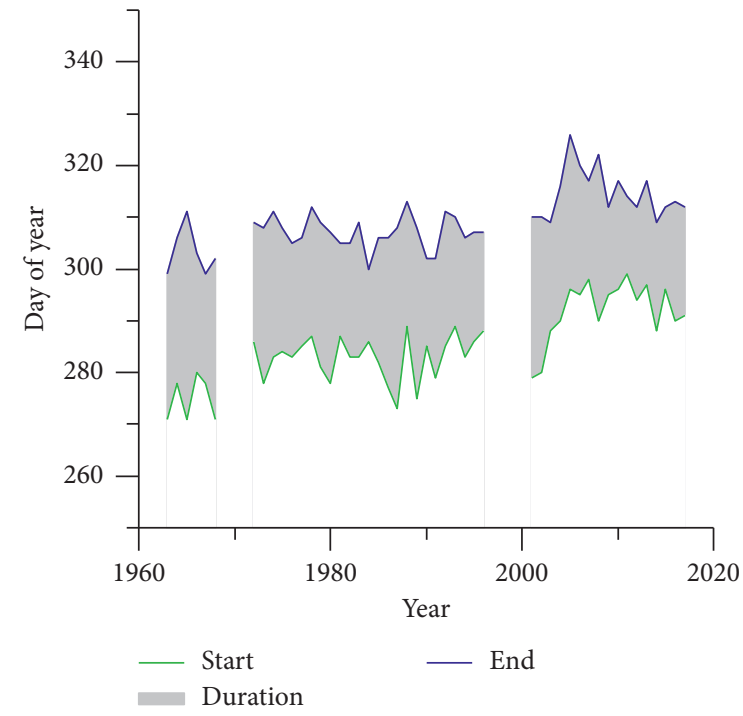

(b)

FIGURE 6: Interannual variation in the best periods for spring and autumn botanical tourism during 1963-2017. (a) Spring. (b) Autumn.

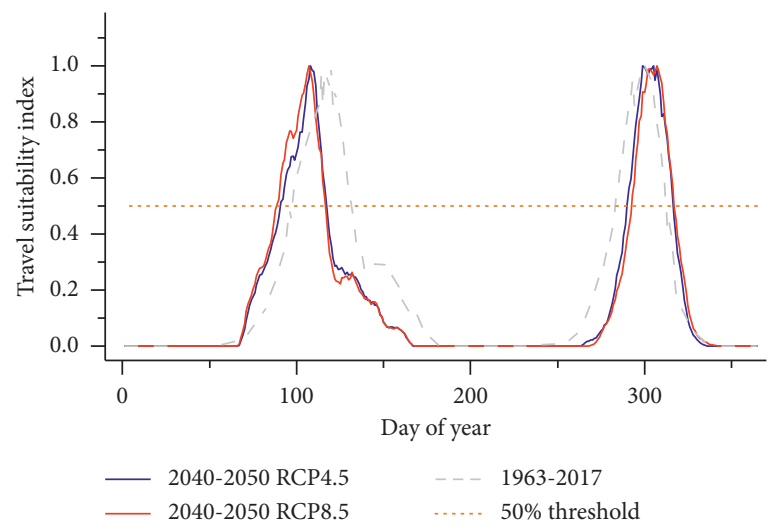

FiguRe 7: Multiyear mean travel suitability index (2040-2050) under two climate scenarios.

autumn leaves viewing. The results showed that the best period for spring flower viewing became earlier with climate warming, which was consistent with the results from previous studies focusing on the changes in the start of the growing season in the United States, Europe, and Australia [39-42]. The advance in spring flowering season may affect 


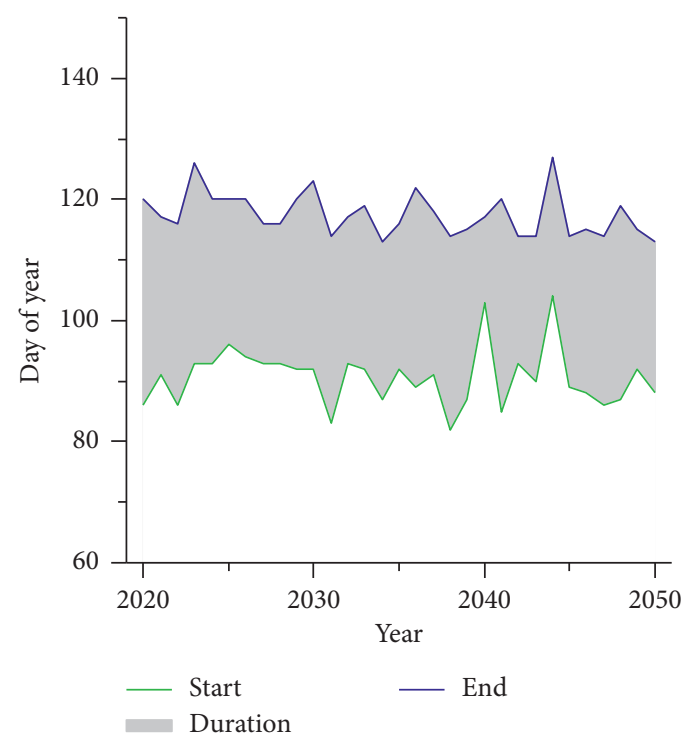

(a)

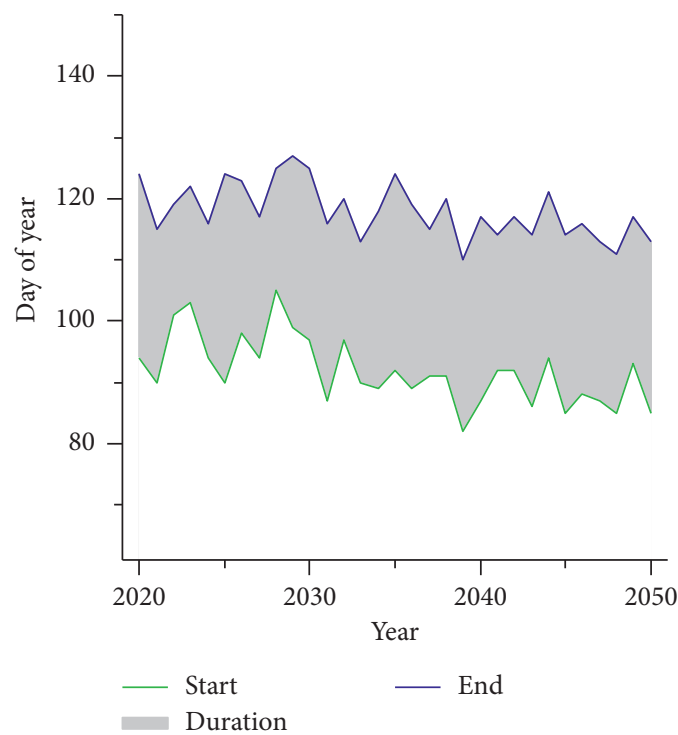

(c)

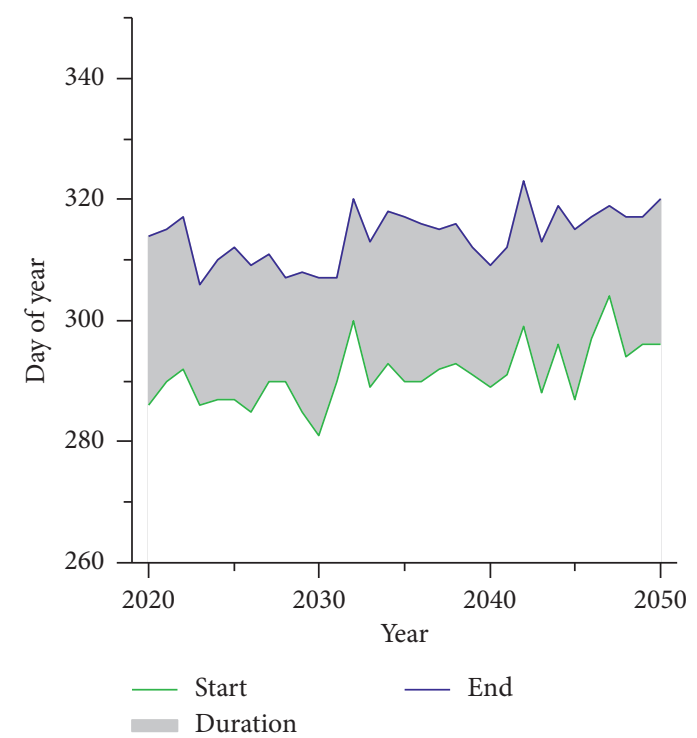

(b)

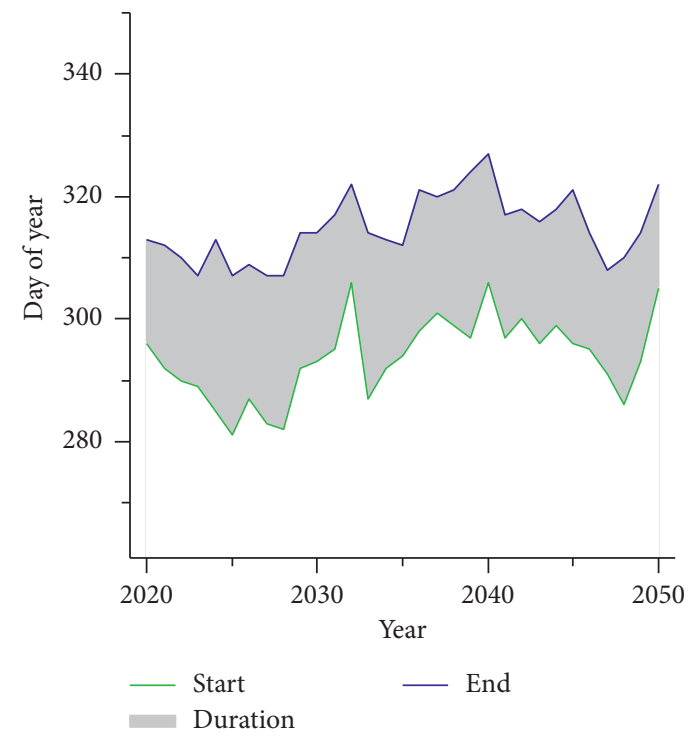

(d)

FIGURE 8: Interannual variations in the best period for spring and autumn botanical tourism under two climate scenarios. (a) RCP 4.5 spring. (b) RCP 4.5 autumn. (c) RCP 8.5 spring. (d) RCP 8.5 autumn.

administrators of scenic spots to arrange the date to hold a blossom festival and the tourists to choose an appropriate time to travel [13].

The best period for autumn leaves viewing derived from the POI was delayed in Beijing. In the study area, September air temperature was decisive for the annual timing of autumn leaves coloring, and warming of $1^{\circ} \mathrm{C}$ led to a delayed beginning and the end date of autumn leaves coloring of 5.3 days and 3.7 days, respectively [43]. In Europe, leaf coloring also was delayed by 1.3 days/decade (1970 to 2000) when the average trend per country was examined [2]. In the northern hemisphere, autumn phenophases of deciduous trees were overall delayed [9]. The change in leaf coloring phenology exerted an essential influence on autumn botanical tourism. For instance, the change in the timing of maple leaf coloring dates has been advantageous to the Japanese maple tourism industry [8].

Since the THI (temperature and relative humidity) and WCI (temperature and wind speed) took different meteorological factors into account when evaluating climate comfort, the degree of comfort could be evaluated more comprehensively by the CCI, which synthesized the two indices. The CCI showed that there were two comfortable periods within a year in Beijing. The mean CCI of the spring and autumn comfortable periods showed strong interannual variation, and no significant linear trends were found from 1963 to 2017. A previous study found that the yearly mean tourism climate index of Beijing urban areas continued to increase from 1951 to 2014 [30]. This result suggested that although the level of comfort averaged from each year 
increased significantly, the level of climate comfort in spring and autumn did not show obvious change.

The TSI established in this study considered both changes in plant phenology and climate comfort, which could comprehensively reflect tourist experience when they attended activities of botanical tourism. If the administrators of the scenic spots did not adjust the date of spring blossom or autumn leaves festival according to the phenophases and climate of the current year, it would cause the mismatch between the travel dates of tourists and the best periods for botanical tourism. Too early start of the festival may lead to the situation that tourists have fewer flowers to view, which may reduce tourist satisfaction. On the contrary, too late start or too early end of the festival would waste the tourism resources and reduce the income of tourist attractions. For example, the cherry blossom festival of Yuyuantan Park, Beijing, received 170,000 tourists in 2000 [43], which was $15 \%$ less than the previous year due to the mismatch between the start date and flowering period of cherries, as well as the influence of frequent sandstorms [44]. Therefore, we suggested that the administrator of scenic spots and the organizers of the activities related to botanical tourism should consider the best period derived from TSI when determining the time to hold the festival. A perfect match between the date of spring blossom (or autumn leaves festival) and the best season of botanical tourism could bring better tourism experience to tourists, which would help attract more visitors and improve the economic benefits of scenic spots.

In the future, the best period for spring and autumn botanical tourism would become shorter compared to the past several decades, which may hurt the development of botanical tourism in Beijing. The reduction in the duration of the best period for botanical tourism would make the time to attend the related tourism activities more concentrated, which may lead to the traffic congestion around the tourist attractions and the crowdedness inside the tourist attractions. Thus, the shortened duration of the best period for botanical tourism would hurt the tourism industry.

In addition to plant phenology, wind speed, temperature, and humidity, other factors also affected tourism, especially air quality [45]. Regional haze (PM 2.5) has been one of the most disastrous weather events in China in recent years [46]. Haze had many adverse effects on botanical tourism [47]. Haze could block the sunlight and thus affect the phenology of ornamental plants and disrupt the arrangement of blossom festivals. For example, the haze reduced the quality of flowers (freshness, vibrancy, and color) for peony (Paeonia suffruticosa) and resulted in the disorder of flowering season (especially for varieties sensitive to sunlight), which affected the economic and social benefits of botanical tourism destinations such as Luoyang and Heze, China [48]. Furthermore, haze often led to widespread flight delays or cancellations and temporarily closed highways, which may affect tourists' travel to botanical tourism destinations. Haze was also prone to causing traffic accidents, increasing the risk of self-driving travel [49]. The haze also influenced tourist behavioral intention during the flowering or leaf coloring period since it has the potential to adversely impact public health [50]. Therefore, future research was needed to clarify the impact of haze on botanical tourism.

In this study, we combined the previously proposed indices (THI and WCI) to construct CCI. Thus, we only considered three climatic factors (temperature, humidity, and wind speed) and did not involve precipitation. This was because THI and WCI were the indices that were recommended by the China Meteorological Administration due to their applicability to the climate of China [51]. Furthermore, the air temperature and relative humidity could to some extent reflect the influence of precipitation on climate comfort, since the temperature was low and relative humidity was high on rainy days. The most important reason was that the uncertainty involved in forecasting precipitation was larger than temperature [52]. Including precipitation in the climate comfort index would cause considerable uncertainty when predicting future degrees of climate comfort. Even so, several studies take precipitation into account when calculating the tourism climate index $[29,30,53]$. Therefore, we needed to compare the different indices of climate comfort in the future.

\section{Conclusion}

In this study, we constructed a travel suitability index (TSI) by combining the phenological ornamental index (POI) and climate comfort index (CCI) to describe the suitability of different dates for botanical tourism. Subsequently, we selected Beijing as the study area and calculated the best period for spring and autumn botanical tourism from 1963 to 2017 based on the TSI. The results showed that the best period for spring botanical tourism in Beijing was between April 7 and May 10, while the best period for autumn botanical tourism was from October 10 to November 7. In 2040-2050, the best period for spring botanical tourism would start 7-9 days earlier, end 14-15 days earlier, and last 6-7 days shorter than that in the past 55 years. The best period for autumn botanical tourism would start 6-9 days later, 4 days later, and last 2-5 days shorter than that in the past 55 years. The potential decrease in the duration of the best period for botanical tourism may have a negative impact on the development of botanical tourism in Beijing.

Therefore, it is necessary to take corresponding measures to deal with the impact of climate change on botanical tourism. First, the scenic spots should improve tourism infrastructure to enhance their reception capacity and add the types of ornamental plants to prolong the flowering season. Second, the administrators of the scenic spots should adjust the date for holding the blossom (or leaf coloring) festivals according to the phenophases predicted by the phenological models. Third, establishing a real-time information distribution platform for the public is to report the daily situations of flowering and leaf coloring of different species. This could guide the public to choose the proper time to travel. At last, the government could develop flexible vacation arrangements, allowing visitors to enjoy the activities of botanical tourism at the best time. 


\section{Data Availability}

The phenological data could be downloaded from the National Earth System Science Data Center (http://www. geodata.cn, in Chinese). The meteorological data were available from the National Meteorological Information Center (http://data.cma.cn/en). The future climatic data were derived from the Coupled Model Intercomparison Project Phase 5 (CMIP5) established by the World Climate Research Programme (WCRP) (esgf-node.llnl.gov/search/ cmip5).

\section{Conflicts of Interest}

The authors declare no conflicts of interest.

\section{Acknowledgments}

This research was supported by the National Key R\&D Program of China (Grant no. 2018YFA0606102), National Natural Science Foundation of China (Grant no. 41871032), Youth Innovation Promotion Association, CAS (Grant no. 2018070), and Program for "Kezhen"Excellent Talents in IGSNRR, CAS (Grant no.2018RC101).

\section{Supplementary Materials}

Table S1: the summary of species investigated in this study. Table S2: validity of phenological models. FFD: First flowering date; EFD: end of flowering date. BLC: beginning of leaf coloring; ELC: end of leaf coloring. N: number of species; RMSE: the root mean square error averaged from all species; R2: the goodness of fit averaged from all species; Sig: percentage of species with significant correlation $(P<0.05)$ between predicted date and observed date. Figure S1: multiyear mean phenological ornamental index under different climatic scenarios. Figure S2: multiyear mean climate comfort index under different climatic scenarios. (Supplementary Materials)

\section{References}

[1] M. B. Gómez Martín, "Weather, climate and tourism a geographical perspective," Annals of Tourism Research, vol. 32, no. 3, pp. 571-591, 2005.

[2] A. Menzel, T. H. Sparks, N. Estrella et al., "European phenological response to climate change matches the warming pattern," Global Change Biology, vol. 12, no. 10, pp. 1969-1976, 2006.

[3] A. Bigano, J. Hamilton, and R. J. Tol, "The impact of climate on holiday destination choice," Climatic Change, vol. 76, no. 3-4, pp. 389-406, 2006.

[4] D. Maddison, "In Search of warmer climates? The impact of climate change on flows of British tourists," Climatic Change, vol. 49, no. 1-2, pp. 193-208, 2001.

[5] A. Bock, T. H. Sparks, F. Estrella et al., "Changes in first flowering dates and flowering duration of 232 plant species on the island of Guernsey," Global Change Biology, vol. 20, no. 11, pp. 3508-3519, 2014.

[6] K. Bolmgren, D. Vanhoenacker, and A. J. Miller-Rushing, "One man, 73 years, and 25 species. Evaluating phenological responses using a lifelong study of first flowering dates," International Journal of Biometeorology, vol. 57, no. 3, pp. 367-375, 2013.

[7] T. T. Hoye, E. Post, N. M. Schmidt et al., "Shorter flowering seasons and declining abundance of flower visitors in a warmer Arctic," Nature Climate Change, vol. 3, pp. 759-763, 2013.

[8] J. Liu, H. Cheng, D. Jiang et al., "Impact of climate-related changes to the timing of autumn foliage colouration on tourism in Japan," Tourism Management, vol. 70, pp. 262-272, 2018.

[9] A. L. Gill, A. S. Gallinat, R. Sanders-Demott et al., "Changes in autumn senescence in northern hemisphere deciduous trees: a meta-analysis of autumn phenology studies," Annals of Botany, vol. 116, no. 6, pp. 875-888, 2015.

[10] U. Chung, L. Mack, J. I. Yun et al., "Predicting the timing of cherry blossoms in Washington, DC and mid-atlantic States in response to climate change," Plos One, vol. 6, no. 11, 2011.

[11] J. Hur and J.-B. Ahn, "Seasonal prediction of regional surface air temperature and first-flowering date over South Korea," International Journal of Climatology, vol. 35, no. 15, pp. 4791-4801, 2015.

[12] R. Sakurai, S. K. Jacobson, H. Kobori et al., "Culture and climate change: Japanese cherry blossom festivals and stakeholders' knowledge and attitudes about global climate change," Biological Conservation, vol. 144, no. 1, pp. 654-658, 2011.

[13] L. Wang, Z. Ning, H. Wang, and Q. Ge, "Impact of climate variability on flowering phenology and its implications for the schedule of blossom festivals," Sustainability, vol. 9, no. 7, p. 1127, 2017.

[14] K. Blazejczyk, Y. Epstein, K. Jendritzky, H. Staiger, and B. Tinz, "Comparison of UTCI to selected thermal indices," International Journal of Biometeorology, vol. 56, no. 3, pp. 515-535, 2012.

[15] F. C. Houghten and C. P. Yagloglou, "Determining lines of equal comfort," Society Of Heating And Ventilating Engineers, vol. 29, pp. 163-176, 1923.

[16] C. P. Yaglou and D Minard, "Control of heat casualties at military training centers," Archives of Industrial Health, vol. 16, no. 4, pp. 302-316, 1957.

[17] E. C. Thom, "A new concept of cooling degree days," Air Condition Heat Ventilation, vol. 54, no. 6, pp. 73-80, 1957.

[18] P. Siple and C. Passel, "Measurements of dry atmospheric cooling in subfreezing temperatures," Proceedings of the American Philosophical Society, vol. 89, no. 1, pp. 177-199, 1945.

[19] A. P. Gagge, A. P. Fobelets, and L. G. Berglund, "A standard predictive index of human response to the thermal environment," Ashrae Transactions, vol. 92, no. 2, pp. 709-731, 1986.

[20] J. A. J. Stolwijk, A Mathematical Model of Physiological Temperature Regulation in Man, National Aeronauticsand Space Administration, Washington, DC, USA, 1971.

[21] H. Staiger, G. Laschewski, and A. Grätz, "The perceived temperature - a versatile index for the assessment of the human thermal environment. Part A: scientific basics," International Journal of Biometeorology, vol. 56, no. 1, pp. 165-176, 2012.

[22] R. R. Gonzalez, Y. Nishi, and A. P. Gagge, "Experimental evaluation of standard effective temperature a new biometeorological index of man's thermal discomfort," International Journal of Biometeorology, vol. 18, no. 1, pp. 1-15, 1974.

[23] H. Mayer and P. Hoppe, "Thermal comfort of man in different urban environments," Theoretical and Applied Climatology, vol. 38, no. 1, pp. 43-49, 1987. 
[24] G. Jendritzky, R. de Dear, and G. Havenith, "UTCI-Why another thermal index?" International Journal of Biometeorology, vol. 56, no. 3, pp. 421-428, 2012.

[25] P. Bröde, D. Fiala, K. Błażejczyk et al., "Deriving the operational procedure for the universal thermal climate index (UTCI)," International Journal of Biometeorology, vol. 56, no. 3, pp. 481-494, 2012.

[26] H. Farajzadeh, M. Saligheh, and B. Alijani, "Application of universal thermal climate index in Iran from tourism perspective," Nature Climate Change, vol. 5, pp. 117-138, 2016.

[27] Z. Sajad, H. Naser, S. H. Elahi et al., "Comparing universal thermal climate index (UTCI) with selected thermal indices/ environmental parameters during 12 months of the year," Weather and Climate Extremes, vol. 19, pp. 49-57, 2018.

[28] D. Mihăilă, P. I. Bistricean, and A. E. Briciu, "Assessment of the climate potential for tourism.Case study:the north-east development region of Romania," Theoretical and Applied Climatology, vol. 137, pp. 601-622, 2019.

[29] Q.-p. Cheng and F.-l. Zhong, "Evaluation of tourism climate comfort in the Grand Shangri-La region," Journal of Mountain Science, vol. 16, no. 6, pp. 1452-1469, 2019.

[30] L. XiangY. H. Zhang et al., "Assessment for tourism climate and its risk for urban area of Beijing," Arid Land Geography, vol. 39, no. 3, pp. 654-661, 2016.

[31] R. H. Moss, J. A. Edmonds, K. A. Hibbard et al., "The next generation of scenarios for climate change research and assessment," Nature, vol. 463, no. 7282, pp. 747-756, 2010.

[32] M. Hessami, P. Gachon, T. B. M. J. Ouarda, and A. St-Hilaire, "Automated regression-based statistical downscaling tool," Environmental Modelling \& Software, vol. 23, no. 6, pp. 813-834, 2008.

[33] D. Scott and G. McBoyle, "Using a tourism climate index to examine the implications of climate change for climate as a tourism resource," in Proceedings of the first International Workshop on Climate, Tourism and Recreation, Freiburg, Germany, 2001.

[34] NationalResearchCouncil, A guide to environmental research on animals, vol. 374, National Academy of Sciences, Washington, DC, USA, 1971.

[35] W. E. Woodson, P. Tillman, and B. Tillman, Human Factors Design Handbook, p. 815, McGraw-Hill, New York, NY, USA, 1981.

[36] I. Chuine, "A unified model for budburst of trees," Journal of Theoretical Biology, vol. 207, no. 3, pp. 337-347, 2000.

[37] N. Delpierre, E. Dufrene, K. Soudani et al., "Modellinginterannual and spatial variability of leaf senescence for three deciduous tree species in France," Agricultural and Forest Meteorology, vol. 149, no. 6-7, pp. 938-948, 2009.

[38] I. Chuine, P. Cour, and D. D. Rousseau, "Fitting models predicting dates of flowering of temperate-zone trees using simulated annealing," Plant, Cell \& Environment, vol. 21, no. 5, pp. 455-466, 1998.

[39] L. E. Chambers, R. Altwegg, C. Barbraud et al., "Phenological changes in the southern hemisphere," Plos One, vol. 8, no. 10, Article ID e75514, 2013.

[40] M. D. Schwartz, T. R. Ault, and J. L. Betancourt, "Spring onset variations and trends in the continental United States: past and regional assessment using temperature-based indices," International Journal of Climatology, vol. 33, no. 13, pp. 2917-2922, 2013.

[41] B. Szabó, E. Vincze, and B. Czúcz, "Flowering phenological changes in relation to climate change in Hungary," International Journal of Biometeorology, vol. 60, no. 9, pp. 13471356, 2016.
[42] C. Ziello, A. Böck, N. Estrella, D. Ankerst, and A. Menzel, "First flowering of wind-pollinated species with the greatest phenological advances in Europe," Ecography, vol. 35, no. 11, pp. 1017-1023, 2012.

[43] Q. Ge, J. Dai, J. Liu, S. Zhong, and H. Liu, "The effect of climate change on the fall foliage vacation in China," Tourism Management, vol. 38, pp. 80-84, 2013.

[44] Beijing Municipal Forestry and Parks Bureau, Beijing parks yearbook, Beijing municipal forestry and parks bureau, Beijing, China, 2000.

[45] Y. Chen, "Features of weather/climate over China in 2000," Meteorological Knowledge, vol. 27, no. 4, pp. 20-24, 2001.

[46] M. Li and L. Zhang, "Haze in China: current and future challenges," Environmental Pollution, vol. 189, pp. 85-86, 2014.

[47] D. Scott, G. McBoyle, and M. Schwartzentruber, "Climate change and the distribution of climatic resources for tourism in North America," Climate Research, vol. 27, pp. 105-117, 2004.

[48] C. C. Tang, X. Q. Liu, and C. Y. Song, "Impact of haze on regional tourism industry and its countermeasures," Geography and Geo-Information Science, vol. 32, no. 5, pp. 121-126, 2016.

[49] L. Hein, M. J. Metzger, and A. Moreno, "Potential impacts of climate change on tourism; a case study for Spain," Current Opinion in Environmental Sustainability, vol. 1, no. 2, pp. 170-178, 2009.

[50] K. Tervo, "The operational and regional vulnerability of winter tourism to climate variability and change: the case of the Finnish nature-based tourism entrepreneurs," Scandinavian Journal of Hospitality and Tourism, vol. 8, no. 4, pp. 317-332, 2008.

[51] Standardization administration, Climatic Suitability Evaluating on Human Settlement, Standards Press of China, Beijing, China, 2012.

[52] J. Feng, D. K. Lee, C. Fu et al., "Comparison of four ensemble methods combining regional climate simulations over Asia," Meteorology and Atmospheric Physics, vol. 111, no. 1-2, pp. 41-53, 2011.

[53] H. G. T. Olya and H. Alipour, "Risk assessment of precipitation and the tourism climate index," Tourism Management, vol. 50, pp. 73-80, 2015. 